\title{
Prevalence and Trends in Prepregnancy Normal Weight - 48 States, New York City, and District of Columbia, 2011-2015
}

\author{
Nicholas P. Deputy, $\mathrm{PhD}^{1,2}$; Bhanuja Dub, $\mathrm{MPH}^{1,3}$; Andrea J. Sharma $\mathrm{PhD}^{1}$
}

Women who enter pregnancy at a weight above or below normal weight, defined as a body mass index (BMI) of 18.5-24.9 (calculated as weight in $\mathrm{kg} /$ height in $\mathrm{m}^{2}$ ), are more likely to experience adverse pregnancy outcomes and to have infants who experience adverse health outcomes. For example, prepregnancy underweight $(\mathrm{BMI}<18.5)$ increases the risk for small-for-gestational-age births, whereas prepregnancy overweight (BMI 25.0-29.9) and obesity (BMI $\geq 30.0$ ) increase risks for cesarean delivery, largefor-gestational-age births, and childhood obesity (1). Given these outcomes, Healthy People 2020 includes an objective to increase the proportion of women entering pregnancy with a normal weight from $52.5 \%$ in 2007 to $57.8 \%$ by $2020{ }^{*}$ Because recent trends in prepregnancy normal weight have not been reported, CDC examined 2011-2015 National Vital Statistics System (NVSS) natality data, which included prepregnancy BMI. In 2015, for 48 states, the District of Columbia (DC), and New York City (NYC) combined, the prevalence of prepregnancy normal weight was 45.0\%; prevalence ranged from $37.7 \%$ in Mississippi to $52.2 \%$ in DC. Among 38 jurisdictions with prepregnancy BMI data during 2011-2015, normal weight prevalence declined from $47.3 \%$ to $45.1 \%$; declines were observed in all jurisdictions but were statistically significant for 27 jurisdictions after standardizing to the 2011 national maternal age and race/ethnicity distribution. Screening women's BMI during routine clinical care provides opportunities to promote normal weight before entering pregnancy.

NVSS collects demographic and health information for live births in 50 states $^{\dagger}$ and DC via the U.S. Standard Certificate of Live Birth (birth certificate), which was revised in 2003 to include maternal height and prepregnancy weight. Height and prepregnancy weight are self-reported or abstracted from medical records ${ }^{\S}$ and are used by NVSS to calculate prepregnancy BMI.

\footnotetext{
* Healthy People 2020 Maternal, Infant and Child Health (MICH) Objective 16.5 for healthy prepregnancy weight (defined as normal weight BMI) was developed using state-specific surveillance data that rely on self-reported height and prepregnancy weight reported approximately $2-7$ months postpartum. Data from 28 states participating in the Pregnancy Risk Assessment Monitoring System and data from California's Maternal and Infant Health Assessment survey contributed to the development of this objective. https://www.healthypeople.gov/2020/ topics-objectives/topic/Maternal-Infant-and-Child-Health/objectives.

$\dagger$ Natality data from New York City are reported separately from those for the state of New York and are not included in New York estimates.

$\$$ Per National Center for Health Statistics guidance for completing the 2003 revision of the U.S. Standard Certificate of Live Birth, the preferred source for prepregnancy weight and height is self-report by the mother around the time of delivery, which is recorded on the Mother's Worksheet (https://www.cdc. gov/nchs/data/dvs/momswkstf_improv.pdf). Maternal height and prepregnancy weight recorded in the mother's prenatal care record may be used as an alternative source. https://www.cdc.gov/nchs/data/dvs/birth_edit_specifications.pdf.
}

The revised birth certificate was used in 36 states, DC, and NYC by 2011 and was used in 48 states, DC, and NYC by 2015 (representing 83\% and 97\% of all live births in 2011 and 2015, respectively). Births to U.S. resident mothers in states adopting the revised birth certificate by January 1 of each year were eligible for analyses $(17,906,182$ mothers, representing $90 \%$ of all U.S. births during 2011-2015).** From these records, those with missing BMI (732,052) were excluded, resulting in 17,174,130 records for analysis ( $96 \%$ of births eligible for this analysis).

Prepregnancy BMI was categorized as underweight $(<18.5)$, normal weight (18.5-24.9), overweight (25.0-29.9), or obese $(\geq 30.0)$; for some analyses, obesity was categorized as class I (BMI $=30.0-34.9)$, class II (35.0-39.9), or class III $(\geq 40.0)$. Overall and jurisdiction-specific prevalences for each prepregnancy BMI category were estimated. Overall and jurisdiction-specific trends were estimated as the percentagepoint difference in prepregnancy normal weight prevalence from 2011 to 2015 for 38 jurisdictions with available data; overall trends for each prepregnancy BMI category were also estimated as the percentage change from 2011 to 2015. Because prepregnancy BMI increases with maternal age and varies by maternal race/ethnicity (2), jurisdiction-specific differences were estimated after directly standardizing each year to the race/ethnicity and age distribution ${ }^{\dagger \dagger}$ of 2011 U.S. resident mothers to facilitate comparisons. Standardized, jurisdictionspecific differences were evaluated using the $\mathrm{z}$-statistic; $\mathrm{p}<0.05$ was considered statistically significant.

For 48 states, DC, and NYC in 2015, the overall prevalence of prepregnancy normal weight was $45.0 \%$; prevalences ranged from $37.7 \%$ in Mississippi to $52.2 \%$ in DC (Table 1). Among 38 jurisdictions with prepregnancy BMI data from 2011 to 2015, prevalence of normal weight declined from $47.3 \%$ to 45.1\%; after standardization, this represented a 1.9 percentagepoint decline $(\mathrm{p}<0.05)$. Declines in prepregnancy normal

\footnotetext{
9 Connecticut and New Jersey did not use the revised birth certificate by January 1, 2015.

** For each year from 2011 to 2015 , the distributions of maternal race/ethnicity and age were not meaningfully different for women residing in states that used the revised birth certificate compared with the entire population of women giving birth in the United States. Additional information can be found in the Birth Data File User's Guide for each year. https://www.cdc.gov/nchs/ data_access/Vitalstatsonline.htm.

i† Race/ethnicity was classified as Hispanic, non-Hispanic white, black, American Indian/Alaska Native, and Asian/Pacific Islander. Age was categorized into the following age groups: $<19,20-24,25-29,30-34$, and $>35$ years.
} 
TABLE 1. Prevalence of prepregnancy normal weight ${ }^{*}$ among women with a live birth, by jurisdiction and year $-48 \mathrm{states},{ }^{\dagger}$ District of Columbia, and New York City, 2011-2015

\begin{tabular}{|c|c|c|c|c|c|c|c|c|c|c|c|}
\hline \multirow[b]{2}{*}{ Jurisdiction } & \multicolumn{5}{|c|}{ No. of live births } & \multicolumn{5}{|c|}{$\%$ of women with prepregnancy normal weight ${ }^{\S}$} & \multirow{2}{*}{$\begin{array}{l}\text { Percentage-point difference } \\
\text { in standardized }{ }^{\uparrow} \text { prevalence } \\
\text { from } 2011 \text { to } 2015\end{array}$} \\
\hline & 2011 & 2012 & 2013 & 2014 & 2015 & 2011 & 2012 & 2013 & 2014 & 2015 & \\
\hline Alabama & 一** & - & - & 57,563 & 58,312 & - & - & - & 42.3 & 40.9 & - \\
\hline Alaska & - & - & 10,871 & 11,101 & 10,956 & - & - & 46.4 & 45.9 & 46.2 & - \\
\hline Arizona & - & - & - & 86,351 & 84,960 & - & - & - & 44.9 & 43.9 & - \\
\hline Arkansas & - & - & - & 37,459 & 37,599 & - & - & - & 42.1 & 42.9 & - \\
\hline California & 474,514 & 477,348 & 470,386 & 481,030 & 473,927 & 48.5 & 48.2 & 47.6 & 47.5 & 46.7 & $-1.7^{\dagger \dagger}$ \\
\hline Colorado & 63,266 & 63,372 & 63,340 & 63,909 & 64,528 & 52.3 & 51.1 & 50.5 & 50.6 & 49.5 & $-2.7^{\dagger \dagger}$ \\
\hline Delaware & 11,059 & 10,916 & 10,696 & 10,849 & 11,071 & 45.1 & 45.1 & 43.8 & 42.7 & 41.0 & $-3.5^{+t}$ \\
\hline District of Columbia & 8,050 & 8,597 & 8,608 & 9,022 & 9,240 & 52.7 & 52.4 & 52.6 & 53.0 & 52.2 & -1.8 \\
\hline Florida & 202,005 & 201,549 & 202,173 & 206,871 & 211,232 & 48.3 & 48.2 & 47.3 & 47.1 & 46.5 & $-1.7^{\dagger \dagger}$ \\
\hline Georgia & 102,287 & 110,951 & 109,530 & 116,260 & 121,378 & 42.6 & 42.3 & 41.5 & 42.3 & 42.1 & -0.2 \\
\hline Hawaii & - & - & - & 17,661 & 17,653 & - & - & - & 48.5 & 47.8 & - \\
\hline Idaho & 22,232 & 22,883 & 22,299 & 22,819 & 22,703 & 50.1 & 49.3 & 48.8 & 48.4 & 47.4 & $-2.8^{\dagger \dagger}$ \\
\hline Illinois & 156,300 & 153,521 & 150,347 & 152,685 & 150,222 & 46.0 & 45.5 & 44.5 & 44.4 & 42.8 & $-2.9^{\dagger \dagger}$ \\
\hline Indiana & 82,794 & 82,545 & 82,442 & 83,736 & 83,727 & 45.0 & 44.4 & 43.2 & 43.1 & 42.0 & $-2.6^{\dagger \dagger}$ \\
\hline lowa & 38,061 & 38,555 & 38,964 & 39,512 & 39,281 & 46.5 & 46.0 & 45.1 & 44.8 & 44.6 & $-1.5^{\dagger \dagger}$ \\
\hline Kansas & 38,588 & 39,479 & 38,095 & 38,676 & 38,999 & 46.8 & 46.3 & 45.9 & 44.5 & 44.0 & $-2.7^{\dagger \dagger}$ \\
\hline Kentucky & 54,413 & 54,873 & 54,706 & 55,653 & 55,397 & 43.7 & 43.0 & 42.2 & 42.1 & 41.1 & $-2.2^{\dagger \dagger}$ \\
\hline Louisiana & 59,214 & 60,165 & 60,920 & 62,428 & 62,191 & 43.8 & 43.1 & 43.0 & 42.5 & 41.3 & $-1.9^{\dagger \dagger}$ \\
\hline Maine & - & - & - & 12,585 & 12,562 & - & - & - & 43.1 & 41.7 & - \\
\hline Maryland & 69,775 & 70,093 & 69,045 & 71,388 & 71,406 & 46.5 & 46.0 & 45.8 & 45.4 & 44.3 & $-2.1^{+\dagger}$ \\
\hline Massachusetts & - & 68,218 & 66,589 & 67,812 & 68,945 & - & 52.5 & 52.4 & 51.9 & 51 & - \\
\hline Michigan & 109,157 & 108,065 & 108,462 & 110,080 & 109,542 & 45.1 & 44.6 & 44.0 & 43.3 & 42.4 & $-2.5^{\dagger \dagger}$ \\
\hline Minnesota & - & 66,583 & 67,735 & 68,472 & 67,775 & - & 45.5 & 45.5 & 44.9 & 43.8 & - \\
\hline Mississippi & - & - & 38,056 & 38,554 & 38,232 & - & - & 39.7 & 39.4 & 37.7 & - \\
\hline Missouri & 74,491 & 74,038 & 73,978 & 74,352 & 74,121 & 47.3 & 47.0 & 46.5 & 46.0 & 45.3 & $-1.8^{\dagger \dagger}$ \\
\hline Montana & 11,761 & 11,652 & 11,963 & 12,241 & 12,458 & 49.0 & 48.8 & 48.5 & 48.0 & 46.5 & -3.5 \\
\hline Nebraska & 25,465 & 25,710 & 25,859 & 26,531 & 26,434 & 48.4 & 48.4 & 47.1 & 46.9 & 46.3 & $-2.1^{\dagger \dagger}$ \\
\hline Nevada & 34,793 & 34,521 & 34,636 & 35,288 & 35,694 & 48.8 & 48.9 & 47.9 & 47.2 & 46.4 & $-1.8^{\dagger \dagger}$ \\
\hline New Hampshire & 11,820 & 11,391 & 11,590 & 11,649 & 11,844 & 50.1 & 49.5 & 48.9 & 47.7 & 47.4 & -2.4 \\
\hline New Mexico & 25,390 & 25,447 & 25,028 & 24,666 & 24,899 & 43.2 & 44.1 & 44.3 & 43.6 & 42.0 & -0.1 \\
\hline New York ${ }^{\S \S}$ & 114,593 & 114,215 & 113,392 & 111,635 & 112,131 & 46.7 & 46.3 & 46.0 & 45.1 & 44.3 & $-2.2^{\dagger \dagger}$ \\
\hline New York City & 117,787 & 118,093 & 115,251 & 116,281 & 115,814 & 53.2 & 53.5 & 53.0 & 52.2 & 52.1 & $-1.3^{\dagger \dagger}$ \\
\hline North Carolina & 116,970 & 116,249 & 116,489 & 118,550 & 117,841 & 46.4 & 45.8 & 45.1 & 45.1 & 44.5 & $-1.8^{\dagger \dagger}$ \\
\hline North Dakota & 9,382 & 9,948 & 10,364 & 11,115 & 11,155 & 41.0 & 41.0 & 42.4 & 41.8 & 40.2 & -2.5 \\
\hline Ohio & 130,723 & 131,056 & 131,785 & 135,214 & 135,442 & 46.9 & 46.7 & 46.2 & 45.7 & 44.8 & $-2.0^{\dagger \dagger}$ \\
\hline Oklahoma & 50,824 & 51,139 & 51,676 & 52,323 & 52,024 & 45.2 & 44.5 & 43.5 & 42.5 & 41.7 & $-3.2^{\dagger \dagger}$ \\
\hline Oregon & 44,311 & 43,917 & 43,909 & 44,675 & 45,098 & 48.5 & 47.9 & 48.2 & 47.7 & 47.0 & $-1.3^{t \dagger}$ \\
\hline Pennsylvania & 130,461 & 128,323 & 126,663 & 133,108 & 130,973 & 49.2 & 48.8 & 48.4 & 48.4 & 47.1 & $-2.0^{\dagger \dagger}$ \\
\hline Rhode Island & - & - & - & - & 10,431 & - & - & - & - & 48.2 & - \\
\hline South Carolina & 56,023 & 55,267 & 55,576 & 56,919 & 57,333 & 42.5 & 42.9 & 41.9 & 41.8 & 41.3 & -0.6 \\
\hline South Dakota & 11,675 & 11,954 & 12,094 & 12,136 & 12,194 & 47.8 & 48.6 & 47.0 & 47.8 & 46.5 & -1.0 \\
\hline Tennessee & 76,586 & 77,402 & 77,400 & 79,112 & 78,735 & 46.5 & 46.5 & 45.9 & 45.2 & 44.7 & $-1.6^{\dagger \dagger}$ \\
\hline Texas & 374,890 & 380,229 & 385,536 & 396,957 & 401,330 & 47.4 & 46.8 & 46.0 & 45.3 & 44.5 & $-1.9^{\dagger \dagger}$ \\
\hline Utah & 49,951 & 50,670 & 50,181 & 50,473 & 50,239 & 54.9 & 54.0 & 53.7 & 53.1 & 51.9 & $-2.4^{\dagger \dagger}$ \\
\hline Vermont & 5,957 & 5,927 & 5,900 & 6,053 & 5,818 & 49.4 & 49.2 & 47.9 & 47.6 & 46.7 & -6.0 \\
\hline Virginia & - & - & 74,145 & 77,879 & 91,400 & - & - & 48.4 & 48.1 & 45.4 & - \\
\hline Washington & 81,676 & 83,051 & 81,723 & 83,821 & 84,917 & 46.4 & 45.9 & 45.5 & 45.3 & 45.9 & -0.4 \\
\hline West Virginia & - & - & - & 19,709 & 19,489 & - & - & - & 42.4 & 40.1 & - \\
\hline Wisconsin & 66,647 & 66,342 & 65,556 & 65,915 & 65,727 & 43.1 & 43.2 & 42.9 & 42.3 & 41.7 & $-1.0^{\dagger \dagger}$ \\
\hline Wyoming & 7,278 & 7,448 & 7,532 & 7,609 & 7,703 & 50.1 & 49.9 & 50.3 & 50.2 & 49.0 & -3.1 \\
\hline $\begin{array}{l}38 \text { jurisdictions with } \\
\text { BMI data from } 2011 \\
\text { to } 2015\end{array}$ & $3,121,169$ & $3,136,901$ & $3,124,094$ & $3,191,541$ & $3,194,768$ & 47.3 & 46.9 & 46.3 & 45.9 & 45.1 & $-1.9^{\dagger \dagger}$ \\
\hline $\begin{array}{l}\text { All jurisdictions with } \\
\text { available data }\end{array}$ & $3,121,169$ & $3,271,702$ & $3,381,490$ & $3,686,687$ & $3,713,082$ & 47.3 & 47.0 & 46.4 & 45.9 & 45.0 & $-2.1^{+\dagger}$ \\
\hline
\end{tabular}

Abbreviation: $\mathrm{BMI}=$ body mass index $(\mathrm{kg} / \mathrm{m} 2)$.

* $\mathrm{BMI}=18.5-24.9$

t Connecticut and New Jersey did not use the revised birth certificate by January 1, 2015.

$\S$ Crude prevalence.

I Standardized to 2011 race/ethnicity and age distribution.

** Revised birth certificate data not available for that jurisdiction during that year.

†† Statistically significant $(\mathrm{p}<0.05)$ decrease in mean prevalence standardized to the 2011 maternal age and race/ethnicity distribution.

$\S \S$ Natality data from New York City are reported separately and are not included in New York state estimates. 
weight were observed in all 38 jurisdictions, but were statistically significant in 27 jurisdictions; declines ranged from 1.0 percentage point $(\mathrm{p}=0.01)$ in Wisconsin to 3.5 percentage points $(\mathrm{p}<0.001)$ in Delaware over the 5 -year period (Table 1$)$.

Corresponding with the decline in prepregnancy normal weight prevalence during 2011-2015, the entire BMI distribution shifted toward a higher BMI (Figure). Specifically, there was an $8 \%$ decrease in the prepregnancy underweight prevalence, while there were $2 \%$ and $8 \%$ increases in overweight and obesity, respectively. Notably, class III obesity prevalence increased more rapidly than did class I or class II obesity (increase of $14 \%$ [class III], compared with $10 \%$ [class II] and $6 \%$ [class I]).

In 2015, jurisdictions with the highest prepregnancy normal weight prevalence (DC, Massachusetts, NYC, and Utah) had the lowest obesity prevalence, whereas jurisdictions with lowest prepregnancy normal weight prevalence (Mississippi and West Virginia) had the highest obesity prevalence (Table 2). Although NYC had a relatively high prevalence of prepregnancy normal weight, it also had the highest prevalence of underweight. Notably, some states exhibited a double burden of higher prevalences of prepregnancy underweight and obesity (Arkansas, Kentucky, and West Virginia).

\section{Discussion}

Among the 48 states, DC, and NYC that implemented the revised birth certificate, the overall prevalence of prepregnancy normal weight in 2015 was $45.0 \%$. Among 38 jurisdictions with prepregnancy BMI data from 2011 to 2015, the prevalence of prepregnancy normal weight declined by $5 \%$, whereas the prevalence of overweight increased by $2 \%$, and the prevalence of obesity (all classes) increased by $8 \%$; taken together, these results suggest movement away from the Healthy People 2020 target for prepregnancy normal weight.

Trends from this analysis extend previous findings and demonstrate continued declines in prepregnancy normal weight prevalence. Data from 20 states participating in the Pregnancy Risk Assessment Monitoring System, a multistate representative surveillance system, found prevalence of prepregnancy normal weight declined from $54.5 \%$ in 2003 to $51.5 \%$ in 2009 (3). Data from the National Health and Nutrition Examination Survey indicate prevalence of normal weight

FIGURE. Prevalences and relative changes in prepregnancy BMI categories* among women with a live birth - 36 states, District of Columbia, and New York City, ${ }^{\dagger}$ 2011-2015

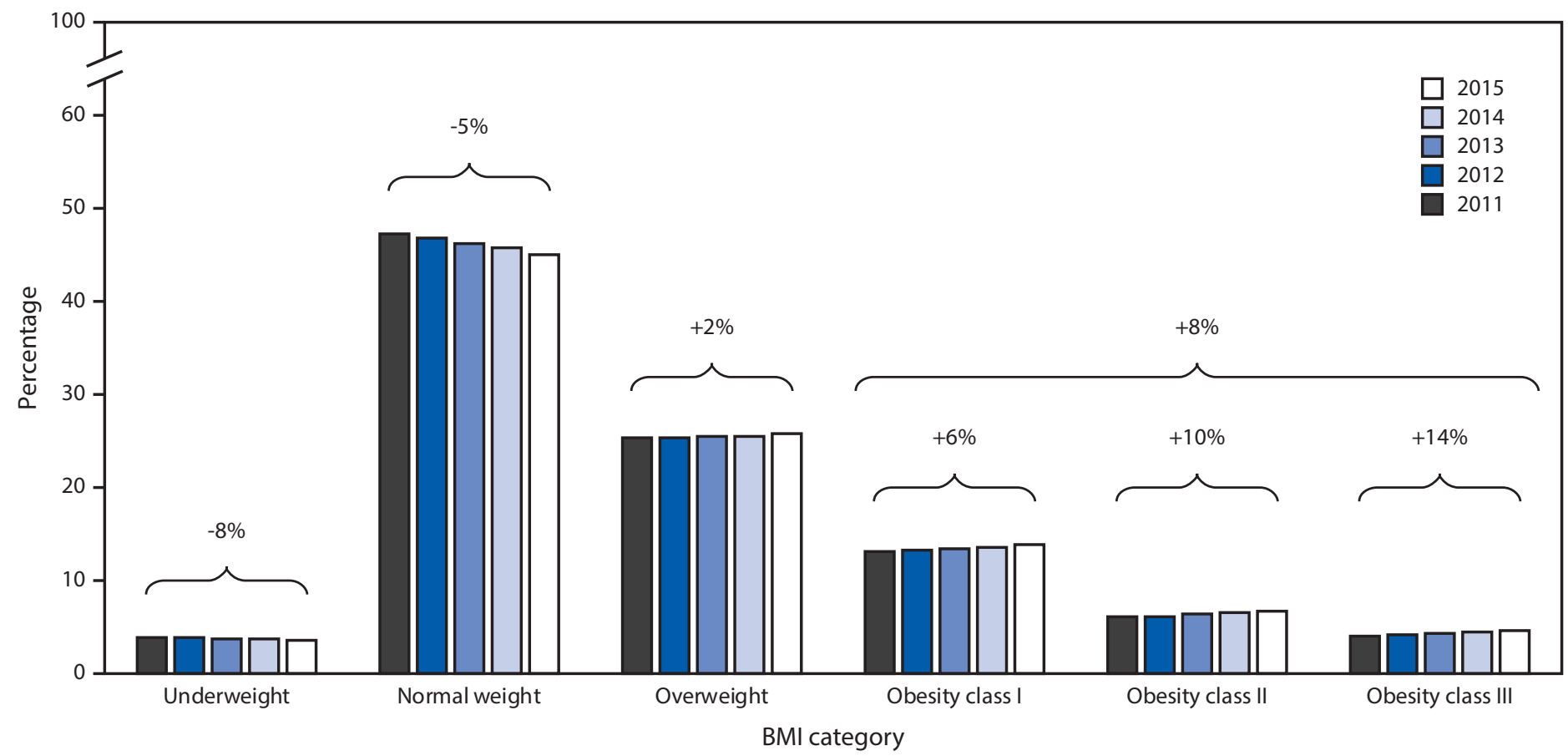

Abbreviation: $\mathrm{BMI}=$ body mass index $\left(\mathrm{kg} / \mathrm{m}^{2}\right)$.

* Prepregnancy BMI was categorized as underweight (BMI <18.5), normal weight (BMI 18.5-24.9), overweight (BMI 25.0-29.9), obesity class I (BMI 30.0-34.9), obesity class II (BMI 35.0-39.9), and obesity class III (BMI $\geq 40.0)$.

† Data are from 38 jurisdictions that utilized the revised birth certificate by January 1, 2011 and, thus, had prepregnancy BMI data during 2011-2015. Jurisdictions included are California, Colorado, Delaware, District of Columbia, Florida, Georgia, Idaho, Illinois, Indiana, lowa, Kansas, Kentucky, Louisiana, Maryland, Michigan, Missouri, Montana, Nebraska, Nevada, New Hampshire, New Mexico, New York, New York City, North Carolina, North Dakota, Ohio, Oklahoma, Oregon, Pennsylvania, South Carolina, South Dakota, Tennessee, Texas, Utah, Vermont, Washington, Wisconsin, and Wyoming (natality data from New York City are reported separately and are not included in New York estimates). 
TABLE 2. Prevalence of prepregnancy BMI categories* among women with a live birth, by jurisdiction -48 states, ${ }^{\dagger}$ District of Columbia, and New York City, 2015

\begin{tabular}{|c|c|c|c|c|}
\hline Jurisdiction & $\%$ Underweight & $\%$ Normal weight & $\%$ Overweight & $\%$ Obese \\
\hline Alabama & 3.9 & 40.9 & 24.8 & 30.4 \\
\hline Alaska & 2.4 & 46.2 & 25.4 & 26.0 \\
\hline Arizona & 3.8 & 43.9 & 26.1 & 26.1 \\
\hline Arkansas & 4.0 & 42.9 & 23.7 & 29.5 \\
\hline California & 3.7 & 46.7 & 26.4 & 23.2 \\
\hline Colorado & 3.5 & 49.5 & 26.1 & 20.9 \\
\hline Delaware & 3.3 & 41.0 & 27.7 & 28.0 \\
\hline District of Columbia & 4.4 & 52.2 & 23.4 & 19.9 \\
\hline Florida & 4.2 & 46.5 & 26.1 & 23.3 \\
\hline Georgia & 3.8 & 42.1 & 25.9 & 28.3 \\
\hline Hawaii & 4.2 & 47.8 & 25.2 & 22.8 \\
\hline Idaho & 3.2 & 47.4 & 25.2 & 24.2 \\
\hline Illinois & 3.1 & 42.8 & 26.8 & 27.3 \\
\hline Indiana & 3.5 & 42.0 & 25.8 & 28.7 \\
\hline lowa & 2.9 & 44.6 & 25.7 & 26.8 \\
\hline Kansas & 3.2 & 44.0 & 26.4 & 26.4 \\
\hline Kentucky & 4.1 & 41.1 & 24.8 & 30.0 \\
\hline Louisiana & 3.8 & 41.3 & 25.1 & 29.9 \\
\hline Maine & 2.0 & 41.7 & 26.2 & 30.1 \\
\hline Maryland & 3.1 & 44.3 & 26.8 & 25.7 \\
\hline Massachusetts & 3.5 & 51.0 & 25.3 & 20.3 \\
\hline Michigan & 3.2 & 42.4 & 25.9 & 28.6 \\
\hline Minnesota & 2.2 & 43.8 & 27.7 & 26.3 \\
\hline Mississippi & 3.8 & 37.7 & 25.0 & 33.5 \\
\hline Missouri & 3.8 & 45.3 & 24.5 & 26.4 \\
\hline Montana & 3.3 & 46.5 & 25.5 & 24.7 \\
\hline Nebraska & 2.9 & 46.3 & 26.0 & 24.7 \\
\hline Nevada & 4.4 & 46.4 & 25.4 & 23.8 \\
\hline New Hampshire & 2.8 & 47.4 & 25.9 & 23.9 \\
\hline New Mexico & 3.9 & 42.0 & 26.8 & 27.2 \\
\hline New York ${ }^{\S}$ & 2.9 & 44.3 & 27.0 & 25.8 \\
\hline New York City & 5.4 & 52.1 & 24.8 & 17.8 \\
\hline North Carolina & 3.8 & 44.5 & 25.2 & 26.6 \\
\hline North Dakota & 2.3 & 40.2 & 27.8 & 29.7 \\
\hline Ohio & 3.7 & 44.8 & 24.6 & 26.9 \\
\hline Oklahoma & 3.8 & 41.7 & 25.7 & 28.8 \\
\hline Oregon & 3.1 & 47.0 & 25.0 & 24.9 \\
\hline Pennsylvania & 3.6 & 47.1 & 24.6 & 24.6 \\
\hline Rhode Island & 2.8 & 48.2 & 26.6 & 22.4 \\
\hline South Carolina & 3.7 & 41.3 & 25.3 & 29.7 \\
\hline South Dakota & 3.0 & 46.5 & 25.7 & 24.9 \\
\hline Tennessee & 4.4 & 44.7 & 24.4 & 26.4 \\
\hline Texas & 3.6 & 44.5 & 26.4 & 25.6 \\
\hline Utah & 4.1 & 51.9 & 23.5 & 20.5 \\
\hline Vermont & 2.8 & 46.7 & 24.3 & 26.1 \\
\hline Virginia & 3.4 & 45.4 & 26.4 & 24.7 \\
\hline Washington & 3.1 & 45.9 & 26.0 & 25.0 \\
\hline West Virginia & 4.7 & 40.1 & 23.9 & 31.3 \\
\hline Wisconsin & 2.2 & 41.7 & 26.3 & 29.8 \\
\hline Wyoming & 3.4 & 49.0 & 24.7 & 22.9 \\
\hline Total & 3.6 & 45.0 & 25.8 & 25.6 \\
\hline
\end{tabular}

Abbreviation: $\mathrm{BMI}=$ body mass index $(\mathrm{kg} / \mathrm{m} 2)$.

* Prepregnancy BMI was categorized as underweight (BMI <18.5), normal weight (BMI 18.5-24.9), overweight (BMI 25.0-29.9), and obese (BMI $\geq 30.0)$.

${ }^{\dagger}$ Connecticut and New Jersey did not use the revised birth certificate by January 1, 2015.

$\S$ Natality data from New York City are reported separately and are not included in New York state estimate.

also declined among nonpregnant women aged 20-34 years, from $42.5 \%$ in $1999-2002$ to $38.1 \%$ in $2011-2014$; similar declines were observed for women aged 35-44 years (4). The declining prevalence of prepregnancy normal weight is concerning because of adverse outcomes associated with entering pregnancy outside of normal weight. For example, prepregnancy underweight increases risks for preterm delivery and small-for-gestational-age births, whereas prepregnancy overweight and obesity increase risks for gestational diabetes mellitus and childhood obesity (1). Moreover, obesity during 


\section{Summary}

What is already known about this topic?

Entering pregnancy outside a normal weight (body mass index [BMI] of $18.5-24.9 \mathrm{~kg} / \mathrm{m}^{2}$ ) is associated with adverse maternal and infant health outcomes; given these outcomes, Healthy People 2020 includes an objective to increase the proportion of women entering pregnancy with normal weight. Recent trends in national or jurisdiction-specific prevalence of prepregnancy normal weight have not been reported.

What is added by this report?

Using data from the revised birth certificate for 48 states, the District of Columbia (DC), and New York City (NYC), this analysis found that the overall prevalence of prepregnancy normal weight was $45.0 \%$ in 2015; prevalence ranged from $37.7 \%$ in Mississippi to $52.2 \%$ in DC. Among 36 states, DC, and NYC with available prepregnancy BMI data from 2011 to 2015, prevalence of normal weight declined from $47.3 \%$ to $45.1 \%$; declines were observed in all jurisdictions but were statistically significant among 27 after standardizing to the 2011 national maternal age and race/ethnicity distribution.

What are the implications for public health practice?

Overall and among most jurisdictions examined, the prevalence of prepregnancy normal weight is decreasing; this suggests movement away from the Healthy People 2020 objective for prepregnancy normal weight. For women of reproductive age, BMI screening during routine clinical visits provides opportunities to address underweight or obesity, promote normal weight upon entering pregnancy, and ultimately help optimize maternal and child health outcomes.

pregnancy has been associated with increased health care service utilization, including longer hospital stays during delivery (5). Before pregnancy, obesity among women of reproductive age is associated with reduced fertility and potentially increased use of fertility treatments (G).

Preconception care is the provision of medical care and interventions that promote optimal health for reproductiveage women and also promote optimal pregnancy outcomes should a pregnancy occur (7). Weight-related screening, counseling, and referral for treatment services are some of the components of preconception care $(7,8)$. The U.S. Preventive Services Task Force recommends that clinicians assess BMI to screen all adults for obesity and offer patients with obesity intensive, multicomponent behavioral interventions or refer patients for these interventions. ${ }^{\$ \$}$ The American College of Obstetricians and Gynecologists (ACOG) recommends BMI screening during routine well-woman visits 9 and recently released an online toolkit ${ }^{\dagger \dagger}$ to facilitate BMI screening and

\footnotetext{
$\$ \$$ https://www.uspreventiveservicestaskforce.org/Page/Document/ RecommendationStatementFinal/obesity-in-adults-screening-and-management. I9 https://www.acog.org/wellwoman.

计 https://www.acog.org/About-ACOG/ACOG-Departments/Toolkits-forHealth-Care-Providers/Obesity-Toolkit.
}

referral for treatment. The toolkit includes an obesity assessment algorithm, counseling methods, treatment options, referral resources, and a coding guide to facilitate reimbursement. For women with underweight BMI, ACOG recommends that clinicians counsel patients about adverse pregnancy outcomes associated with underweight and assess for disordered eating habits (8). Reports indicate prevalence of prepregnancy underweight is highest among women aged $<20$ years (2), possibly because adult BMI criteria are applied to pregnancies among adults and adolescents (9); this categorizes more adolescents as underweight than the pediatric growth charts and results in higher recommended pregnancy weight gain, which has been found to improve pregnancy outcomes among adolescents (9).

The findings in this report are subject to at least three limitations. First, height and prepregnancy weight on the birth certificate are self-reported or abstracted from medical records, which might result in misclassification of BMI category. Second, results of this analysis are not directly comparable to Healthy People 2020 targets for prepregnancy normal weight because these targets were developed using surveillance data from 29 states that exclusively rely on height and prepregnancy weight self-reported 2-7 months postpartum; thus, these targets might differ from those developed using birth certificate data. Notably, the revised birth certificate is a census of all births, which will allow for ongoing monitoring of prepregnancy weight in all states. Finally, data were not available from all states for trend analyses; thus, results do not represent the entire U.S. population of women giving birth.

In 2015 , the nearly national prevalence of prepregnancy normal weight was $45.0 \%$ and prevalence declined from 2011 to 2015 in most jurisdictions, suggesting movement away from the Healthy People 2020 objective to increase the prevalence of prepregnancy normal weight. For all women of reproductive age, BMI screening during routine clinical visits provides opportunities to address underweight or obesity, promote normal weight upon entering pregnancy, and ultimately help optimize maternal and child health outcomes.

\section{Conflict of Interest}

No conflicts of interest were reported.

\footnotetext{
${ }^{1}$ Division of Reproductive Health, National Center for Chronic Disease Prevention and Health Promotion, CDC; ${ }^{2}$ Oak Ridge Institute for Science and Education Fellowship, U.S. Department of Energy; ${ }^{3}$ Rollins School of Public Health, Emory University, Atlanta, Georgia.

Corresponding author: Andrea J. Sharma, AJSharma@cdc.gov, 770-488-5957.

\section{References}

1. Liu P, Xu L, Wang Y, et al. Association between perinatal outcomes and maternal pre-pregnancy body mass index. Obes Rev 2016;17:1091-102. https://doi.org/10.1111/obr.12455
} 
2. Branum AM, Kirmeyer SE, Gregory EC. Prepregnancy body mass index by maternal characteristics and state: data from the birth certificate, 2014. Natl Vital Stat Rep 2016;65:1-11.

3. Fisher SC, Kim SY, Sharma AJ, Rochat R, Morrow B. Is obesity still increasing among pregnant women? Prepregnancy obesity trends in 20 states, 2003-2009. Prev Med 2013;56:372-8. https://doi.org/10.1016/j. ypmed.2013.02.015

4. National Center for Health Statistics. Health, United States, 2015: with special feature on racial and ethnic health disparities. Hyattsville, MD: US Department of Health and Human Services, CDC, National Center for Health Statistics; 2016.

5. Chu SY, Bachman DJ, Callaghan WM, et al. Association between obesity during pregnancy and increased use of health care. N Engl J Med 2008;358:1444-53. https://doi.org/10.1056/NEJMoa0706786
6. Koning AM, Kuchenbecker WK, Groen H, et al. Economic consequences of overweight and obesity in infertility: a framework for evaluating the costs and outcomes of fertility care. Hum Reprod Update 2010;16:246-54. https://doi.org/10.1093/humupd/dmp053

7. Johnson K, Posner SF, Biermann J, et al. Recommendations to improve preconception health and health care-United States. A report of the CDC/ATSDR Preconception Care Work Group and the Select Panel on Preconception Care. MMWR Recomm Rep 2006;55(No. RR-6).

8. Moos MK, Dunlop AL, Jack BW, et al. Healthier women, healthier reproductive outcomes: recommendations for the routine care of all women of reproductive age. Am J Obstet Gynecol 2008;199(Suppl2):S280-9. https://doi.org/10.1016/j.ajog.2008.08.060

9. Rasmussen KM, Yaktine AL, eds. Institute of Medicine and National Research Council. Weight gain during pregnancy: reexamining the guidelines. Washington, DC: The National Academies Press; 2009. 